(c) American Dairy Science Association, 2004.

\title{
A Comparison of Instruments and Laboratories Used to Measure Milk Urea Nitrogen in Bulk-Tank Milk Samples*
}

\author{
R. A. Kohn, K. R. French, and E. Russek-Cohen \\ Department of Animal and Avian Sciences, \\ University of Maryland, College Park 20742
}

\begin{abstract}
The objective of this study was to compare the instruments and laboratories that are currently used for analysis of milk urea nitrogen (MUN) for bulk-tank milk samples. Two replicate samples from each bulk tank on 10 different dairy farms were sent to 12 Dairy Herd Improvement Association (DHIA) laboratories throughout the US for MUN analysis. Two laboratories used 2 different methods for MUN analysis for a total of 14 analyses on 20 samples $(n=280)$. Values of MUN were analyzed using a random effects model with farm, laboratory, and farm $\times$ laboratory variance components. Greater than $98 \%$ of the variance in measured MUN was attributed to farm-to-farm variance for analysis of MUN by the Bentley, CL 10, Foss 6000, and Skalar instruments. However, for the laboratories using the Foss 4000 system, $<60 \%$ of the variance in MUN was attributed to farm-to-farm variance. Laboratories using the Bentley, CL 10, Foss 6000, and Skalar instruments provided slightly different results for MUN analysis, but $>95 \%$ of sample measurements fell within $1.75 \mathrm{mg} /$ $\mathrm{dL}$ of each other. The laboratories using Foss 4000 differed from each other, and $95 \%$ of samples fell within $5 \mathrm{mg} / \mathrm{dL}$ of the CL 10 measurement. Laboratories using the Foss 4000 instrument did not consistently provide measurements of MUN that were similar to each other or to the measurements of the other instruments.
\end{abstract}

(Key words: milk urea nitrogen, milk component analysis)

\section{INTRODUCTION}

Analysis of MUN provides a means to estimate urinary nitrogen excretion (Jonker et al., 1998; Kohn et al., 2002) and to evaluate dairy herd nutrition programs and identify overfeeding or underfeeding of protein (Jonker et al., 1999, 2002b). Mathematical models that

Received August 1, 2003.

Accepted January 9, 2004

Corresponding author: R. A. Kohn; e-mail: rkohn@wam.umd.edu.

*A contribution from the Maryland Agricultural Experiment Station. were developed to interpret MUN results were based on studies using specific procedures to determine MUN. These models will not consistently provide accurate estimates of urinary nitrogen or protein-feeding levels if various laboratories used to measure MUN do not provide equivalent results. Peterson et al. (2004) investigated differences among laboratories for milk samples taken from individual cows. Measurement differences may be greater when using individual cow milk samples compared with bulk-tank samples because milk components (e.g., fat, protein) vary to a greater degree for individual cow milk, and these components influence the accuracy of the measurements (Peterson et al., 2004). The purpose of the current study was to investigate differences among laboratories in measurement of MUN using bulk-tank milk samples and to estimate variance components attributable to instruments and laboratories.

Currently, DHIA laboratories use several different methods for MUN analysis. Many laboratories use the Foss 4000 system (Foss North America Inc., Eden Prairie, $\mathrm{MN}$ ), which is based on associations of MUN in milk samples with infrared spectroscopy. More recently, the Foss 6000 system was developed also using infrared technology. Several automated chemical methods have been developed, including the Bentley Chemspec (Bentley Instruments, Inc., Chaska, MN), CL 10 (Foss North America Inc.), and Skalar (Skalar Inc., Norcross, GA) instruments. The Bentley, CL 10, and Skalar instruments directly measure the change in ammonia after treating the sample with urease. To measure ammonia, the Bentley and Skalar instruments use a Bertholet phenate-hypochlorate reaction and spectrophotometry; the CL 10 instrument uses $\mathrm{pH}$ titration.

\section{MATERIALS AND METHODS}

Bulk-tank milk samples were collected on 10 different Holstein farms in August 2000. Farms were selected among participants in a previous study to reflect a range in MUN values. Samples represented 2 or 4 milkings, and herd size averaged 115 lactating cows and ranged from 38 to 300 . Samples were stored in a cooler with ice and transported directly to the laboratory. On 
Table 1. Mean and variance for milk urea nitrogen (MUN) determined by 14 analyses using different methods on milk from 10 farms.

\begin{tabular}{|c|c|c|c|c|c|c|}
\hline \multirow[b]{2}{*}{ Method $^{1}$} & \multirow[b]{2}{*}{ Mean } & \multirow[b]{2}{*}{ SD } & \multicolumn{4}{|c|}{ Variance attributed to source } \\
\hline & & & Farm & Laboratory & $\begin{array}{l}\text { Farm } \times \\
\text { laboratory }\end{array}$ & Error \\
\hline & $(\mathrm{mg} / \mathrm{dL})$ & & & 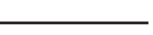 & 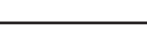 & 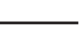 \\
\hline Bentley & 14.21 & 3.91 & $99.4 * *$ & $0.2^{*}$ & 0.2 & 0.2 \\
\hline CL 10 & 13.74 & 3.66 & $99.77 * *$ & $0.05^{* *}$ & $0.11^{* *}$ & 0.07 \\
\hline Foss 4000 & 13.63 & 3.48 & $59.5^{* *}$ & $33.8^{* *}$ & $5.7 * *$ & 1.0 \\
\hline Foss 6000 & 13.74 & 3.28 & $98.1^{* *}$ & 0.1 & $1.1^{*}$ & 0.7 \\
\hline Skalar & 14.41 & 3.92 & $98.8^{* *}$ & $0.9 * *$ & 0.1 & 0.2 \\
\hline
\end{tabular}

${ }^{1}$ Bentley = Bentley Chemspec (Bentley Instruments, Inc., Chaska, MN); CL 10, Foss 4000, and Foss 6000 (Foss North America Inc., Eden Prairie, MN); and Skalar (Skalar Inc., Norcross, GA).

$* P<0.05$.

$* * P<0.01$.

the same day as sample collection, each milk sample was mixed by inverting several times while cold and subdivided into 28 parts of $40 \mathrm{~mL}$ each. The standard preservative used by all laboratories (bronopol and natamycin, D\&F Control Systems, Inc., San Ramon, CA) was added to each sample at this time and mailed overnight in insulated styrofoam containers with ice packs. Twelve different DHIA laboratories were selected to analyze the samples for MUN. Two laboratories analyzed MUN by 2 different methods that were available for a total of 14 analyses. Two replicates from each of 10 farms were subjected to the 14 analyses. The methods used were Bentley Chemspec (4 laboratories), CL 10 (2 laboratories), Foss 4000 (4 laboratories), Foss 6000 (2 laboratories), and Skalar (2 laboratories).

Statistical analyses were performed using SAS (2000). Data for each instrument were analyzed separately. A 2-way random-effects model was fit using Proc Mixed in SAS for each MUN method as follows: $\mathrm{Y}=$ farm + laboratory + farm $\times$ laboratory + error. The percentage of variance among samples attributed to variance from farm, laboratory, or the interaction thereof was determined by dividing the variance component estimate for each component by the total of the variance components. If a method is reproducible, one would expect a small percentage of variation attributable to laboratory and farm $\times$ laboratory variances.

Results from each instrument were compared with the mean of results from the CL 10 instrument (Altman and Bland, 1983). The CL 10 was chosen arbitrarily as a basis for comparison because National DHIA uses it as the standard, but it is not necessarily the most accurate. The Shapiro-Wilk Test was used to verify that data were not inconsistent with normal distribution for each method $(P>0.2)$ or with each laboratory for the Foss $4000(P>0.4)$. The differences between measurements from each method and measurements from the CL 10 analysis were calculated as an indicator of mean bias (relative to the CL 10), and the standard deviation of the differences was used to measure random fluctuations about this mean. The $95 \%$ limits of agreement were calculated as the mean difference \pm 1.96 times the standard deviation of the differences. Thus, we estimate that for $95 \%$ of samples by a given method, the observed value would be greater than the CL 10 value minus the lower limit and less than the CL 10 value plus the upper limit (Bland and Altman, 1995). The linear bias of each method compared with the CL 10 was determined by

Table 2. Milk urea nitrogen (MUN; mg/dL) measured by different methods minus MUN measured by the CL 10 method.

\begin{tabular}{lllll}
\hline & & & \multicolumn{2}{c}{ 95\% Limits of agreement ${ }^{2}$} \\
\cline { 4 - 5 } Method $^{1}$ & Mean & SD & Lower limit & Upper limit \\
\hline Bentley & 0.47 & 0.45 & -0.41 & +1.35 \\
Foss 4000 & -0.21 & 2.51 & -5.13 & +4.71 \\
Foss 6000 & -0.13 & 0.62 & -1.35 & +1.09 \\
Skalar & 0.67 & 0.55 & -0.41 & +1.75 \\
\hline
\end{tabular}

${ }^{1}$ Bentley = Bentley Chemspec (Bentley Instruments, Inc., Chaska, MN), Foss 4000 and Foss 6000 (Foss North America Inc., Eden Prairie, MN), and Skalar (Skalar Inc., Norcross, GA).

${ }^{2}$ For $95 \%$ of samples, the measurement by the indicated method will be greater than the lower limit (reference value minus value indicated) and less than the higher limit (reference value plus value indicated) relative to a measurement by the CL 10; Limits $=1.96$ (SD) \pm mean difference (Bland and Altman, 1995). 
Table 3. Multiple regression of milk urea nitrogen (MUN) measured by Bentley Chemspec (Bentley Instrument, Inc., Chaska, MN) minus MUN measured by CL 10 (Foss North America Inc., Eden Prairie, MN) vs. the average of the 2 measurements for MUN, milk protein percentage, and milk fat percentage.

\begin{tabular}{|c|c|c|c|c|}
\hline Component & $\begin{array}{l}\text { Slope } \\
\text { estimate }^{1}\end{array}$ & $\mathrm{SE}$ & $P<$ & $\mathrm{r}^{2}$ \\
\hline MUN, mg/dL & 0.084 & 0.011 & 0.0001 & 0.211 \\
\hline Fat, \% & -0.86 & -0.17 & -0.0001 & -0.114 \\
\hline Protein, \% & 0.96 & 0.28 & 0.001 & 0.325 \\
\hline
\end{tabular}

${ }^{1}$ Intercept did not differ from 0 .

regression of the difference between the observed MUN and the CL 10 reference values against the mean of the observed MUN and CL 10 values (Altman and Bland, 1983). Regression against the mean of values from the 2 methods, rather than against the value from the reference method alone, is thought to reduce the potential for the variance in the reference measurements to skew the estimate of linear bias (Altman and Bland, 1983). However, unequal variance between the 2 measurements, as observed for the Foss 4000 vs. CL 10, may skew the estimates of linear bias using this approach. Therefore, variance among the laboratories using Foss 4000 was reduced by analyzing each laboratory using that method separately, thus removing the large laboratory effect shown in Table 1. Milk fat percentage, protein percentage, and SCC were also included in the regression model to assess the impact of milk composition on MUN measurement by the different methods. The least significant variables were removed stepwise until only significant variables remained.

\section{RESULTS AND DISCUSSION}

The mean MUN of all samples was $13.96 \mathrm{mg} / \mathrm{dL}$. The lowest farm averaged $6.76 \mathrm{mg} / \mathrm{dL}$, and the highest farm averaged $19.11 \mathrm{mg} / \mathrm{dL}$ across laboratories. These values are realistic because the middle $95 \%$ of MUN values for northeastern US dairy farms were between 5.9 and $19.5 \mathrm{mg} / \mathrm{dL}$ (Jonker et al., 2002a). The means and the standard deviations in MUN across all farms were similar for each method (Table 1). The percentage of variance attributed to variation among farms and laboratories is also shown in Table 1. For the Foss 4000 method, only $59.5 \%$ of the variation in MUN could be attributed to variation from farm to farm, and $33.8 \%$ of the variance was attributed to variance from one laboratory to the next. The farm $\times$ laboratory interaction was also significant for the CL 10, Foss 4000, and Foss 6000 instruments. The significant interaction reflects inconsistencies among laboratories for samples from some farms. For example, some laboratories may have a bigger problem with farms that have high MUN values rather than farms that have low MUN values. For instruments other than the Foss $4000,>98 \%$ of the variation was attributed to farm variance. Thus, any of the laboratories that did not use the Foss 4000 would readily detect differences among farms.

Table 2 shows that all methods provided similar mean MUN compared with the CL 10 instrument. How-

Table 4. Multiple regression of milk urea nitrogen (MUN) measured by Foss 4000 (Foss North America Inc., Eden Prairie, MN) minus MUN measured by CL 10 (Foss North America Inc.) vs. the average of the 2 measurements, milk protein percentage, and milk fat percentage.

\begin{tabular}{lllll}
\hline & $\begin{array}{l}\text { Slope } \\
\text { estimate }\end{array}$ & $\mathrm{SE}$ & $P<$ & $\mathrm{r}^{2}$ \\
\hline Laboratory A & & & & \\
MUN, mg/dL & -0.223 & 0.063 & 0.003 & 0.20 \\
Fat, \% & 5.45 & 1.25 & 0.0006 & 0.12 \\
Protein, \% & -5.88 & 1.78 & 0.0048 & \\
Laboratory B & & & & 0.007 \\
$\quad$ Intercept & -6.55 & 2.10 & 0.05 & 0.11 \\
MUN, mg/dL & -0.104 & 0.047 & 0.0003 & - \\
Fat, \% & 2.65 & 0.59 & & 0.34 \\
Laboratory C & & & 0.0003 & 0.07 \\
Intercept & 17.73 & 3.8 & 0.0001 & 0.41 \\
MUN, mg/dL & -0.48 & 0.080 & 0.0009 & 0.15 \\
Fat, \% & 4.10 & 1.38 & & 0.28 \\
Protein, \% & -9.55 & 2.34 & 0.04 & 0.10 \\
Laboratory D & & & 0.007 & \\
MUN, mg/dL & -0.16 & 0.069 & 0.09 & \\
Fat, \% & 3.32 & 1.08 & & \\
Protein, \% & -3.86 & 2.10 & & \\
\hline
\end{tabular}


ever, the Foss 4000 method yielded a greater standard deviation in the difference from CL 10. If a sample yields a result of $15 \mathrm{mg} / \mathrm{dL}$ by CL 10 , there is a $95 \%$ probability that the Foss 4000 sample would be $>9.87$ and $<19.71$. Therefore, a single sample analyzed by Foss 4000 is difficult to interpret. In contrast, the other methods yielded practically similar results compared with the CL 10, suggesting, for practical purposes, these methods appear comparable.

The regression of differences compared with the CL 10 values are shown in Figures 1 and 2 . A small positive linear bias was evident for Bentley and Skalar instruments compared with the CL 10, and an opposite linear bias was evident for the Foss 6000 compared with the CL 10. It is not possible from these data to say which instrument was most accurate, but the magnitude of the linear bias was small enough that differences are not likely to affect interpretation of MUN results in the field. Peterson et al. (2004) reported that recovery of urea added to raw milk was slightly lower for the CL 10 instrument (85\%) compared with the Bentley (92\%), Foss 6000 (95\%), and Skalar (95\%) instruments, suggesting that the CL 10 may underestimate high MUN values slightly. When milk fat percentage, protein percentage, and SCC were included in the model, these terms were not significant for the Skalar and Foss 6000 instruments. However, results for the Bentley Chemspec are shown in Table 3. Increasing protein percentage was associated with an increase in MUN measurement by Bentley Chemspec compared with the CL 10, and an opposite relationship was apparent for fat percentage. These results differ from those of Peterson et al. (2004), which showed no effect of milk components on measurement of MUN by most methods for spiked samples with a known quantity of urea added. In that study, only fat percentage appeared to affect analysis of MUN and only by the laboratories using the Foss 6000 .

Because of large differences among laboratories using the Foss 4000, linear bias was analyzed separately for each laboratory using Foss 4000 (Table 4; Figure 2). Linear bias compared with the reference CL 10 method was apparent for laboratories using the Foss 4000 method. The higher MUN values were underestimated, and the lower values were overestimated using Foss 4000 compared with the CL 10. Higher milk protein percentage was also associated with lower MUN estimates for the Foss 4000 compared with the CL 10, but the opposite relationship was observed for milk fat percentage. The magnitude of these biases differed for each laboratory. The mean bias is also apparent, with 2 laboratories overestimating MUN and 2 underestimating MUN compared with the CL 10. In contrast to the laboratories using other instruments, none of the laboratories using the Foss 4000 method estimated sim-
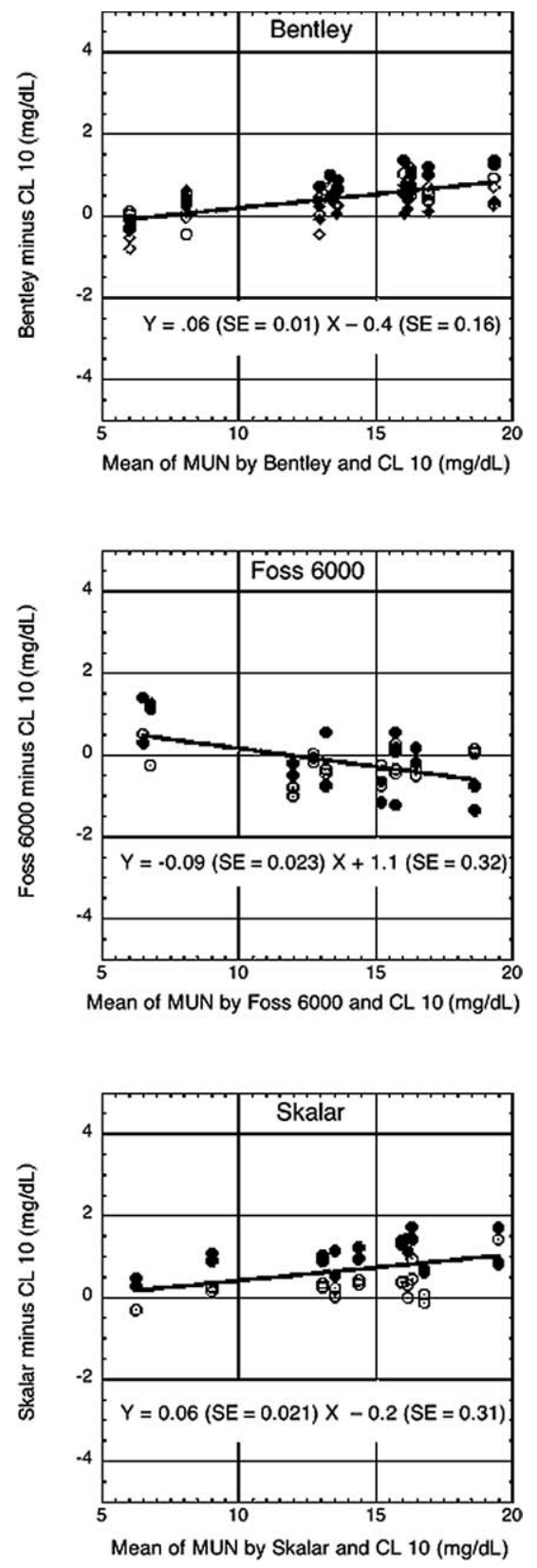

Figure 1. Milk urea nitrogen MUN measured by laboratories using the Bentley (Bentley Instruments, Inc., Chaska, MN), Foss 6000 (Foss North America Inc., Eden Prairie, MN), or Skalar (Skalar Inc., Norcross, GA) systems minus that measured by the CL 10 (Foss North America Inc.) vs. the average of MUN for each method and the CL 10. Different symbols represent different laboratories. Lines indicate linear bias $(P<0.05)$ compared with the CL 10 measurements.

ilar MUN as the CL 10. For the Foss 4000 instrument, much of the variance in MUN was due to laboratory or the interaction of laboratory $\times$ farm. This observation suggests that better methods of calibration from laboratory to laboratory may increase the consistency of the 

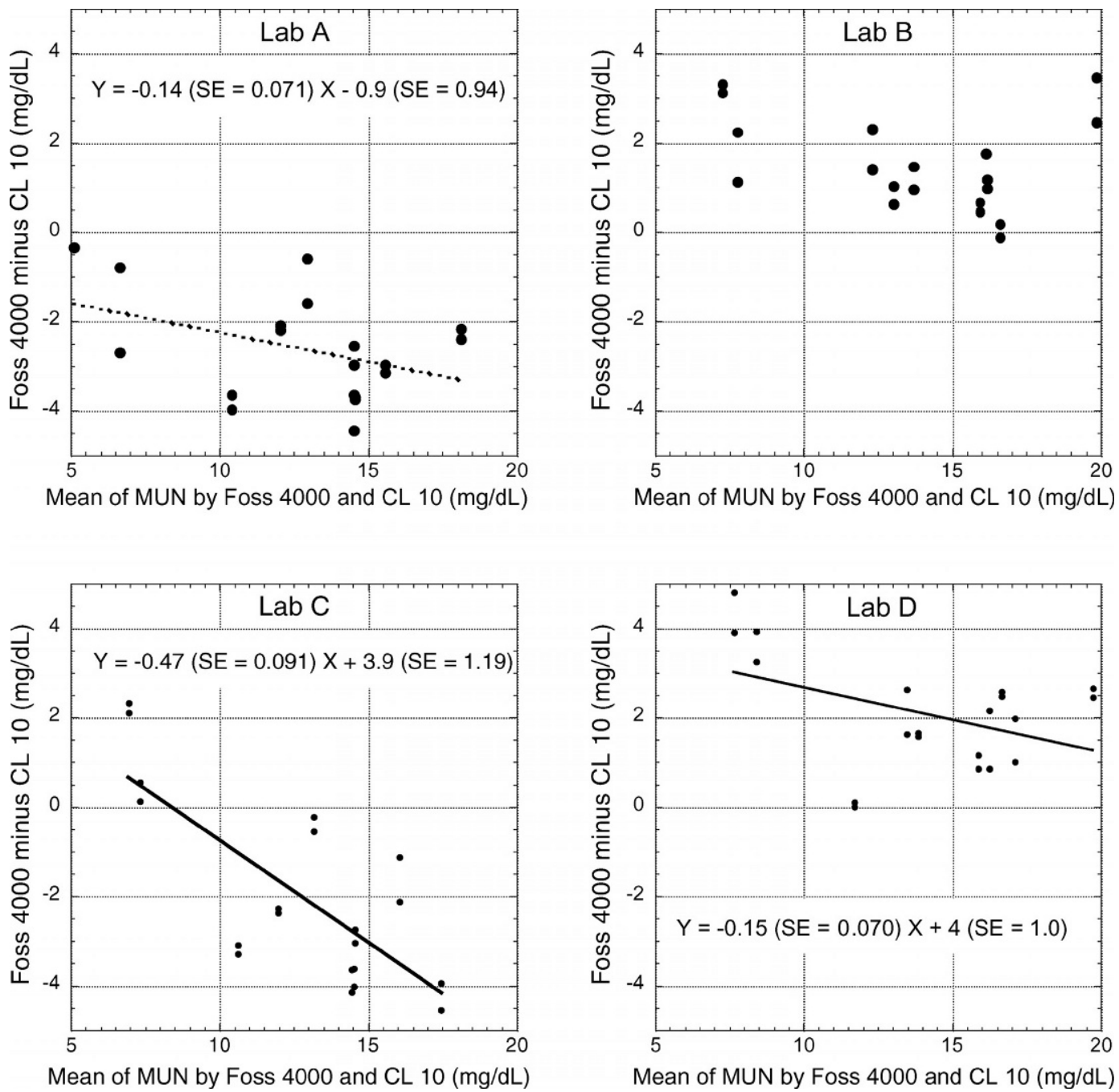

Figure 2. Milk urea nitrogen (MUN) measured by laboratories using the Foss 4000 system (Foss North America Inc., Eden Prairie, MN) minus that measured by the CL 10 (Foss North America Inc.) vs. the average of MUN for each laboratory and the CL 10. Solid lines indicate linear bias $(P<0.05)$, and dashed line indicates tendency of linear bias $(P<0.1)$

measurements made across laboratories. Each of the managers of the laboratories using the Foss 4000 indicated that they use the same randomly selected milk samples provided by National DHIA for monthly calibration, but the range in MUN among these samples may not be adequate to adjust the slope of the calibration curve.

These results are similar to those reported by $\mathrm{Pe}-$ terson et al. (2004) for individual cow milk samples. In that study, recovery of urea added to raw milk samples ranged from 30 to $64 \%$ for laboratories using the Foss 4000 instruments, and there was substantial variation from laboratory to laboratory; recovery of MUN was $>85 \%$ for laboratories using the other instruments.

\section{CONCLUSION}

The MUN measurements from the Bentley Chemspec, Skalar, and Foss 6000 automated systems were slightly different from the CL 10 for bulk-tank milk samples taken from several different farms. The 4 laboratories using the Foss 4000 instrument for MUN did not provide measurements that were consistent with each other or with the other instruments.

\section{REFERENCES}

Altman, D. J., and J. M. Bland. 1983. Measurement in medicine: The analysis of method comparison studies. Statistician 32:307-317.

Bland, M. J., and D. G. Altman. 1995. Comparing methods of measurement: Why plotting difference against a standard method is misleading. Lancet 346:1085-1087. 
Jonker, J. S., R. A. Kohn, and R. A. Erdman. 1998. Using milk urea nitrogen to predict nitrogen excretion and utilization efficiency in lactating dairy cattle. J. Dairy Sci. 81:2681-2692.

Jonker, J. S., R. A. Kohn, and R. A. Erdman. 1999. Milk urea nitrogen target concentrations for lactating dairy cows fed according to National Research Council recommendations. J. Dairy Sci. 82:1261-1273.

Jonker, J. S., R. A. Kohn, and J. High. 2002a. Dairy herd management practices that impact nitrogen utilization efficiency. J. Dairy Sci. $85: 1218-1226$.
Jonker, J. S., R. A. Kohn, and J. High. 2002b. Use of milk urea nitrogen to improve dairy cow diets. J. Dairy Sci. 85:939-946.

Kohn, R. A., K. E. Kalscheur, and E. Russek-Cohen. 2002. A comparison of models to measure milk urea and urinary $\mathrm{N}$ excretion. J. Dairy Sci. 85:227-234.

Peterson, A. B., E. Russek-Cohen, and R. A. Kohn. 2004. Comparison of analytical methods and the influence of milk components on milk urea nitrogen recovery. J. Dairy Sci. 87:1747-1750.

SAS User's Guide, Version 8. 2000. SAS Inst., Inc., Cary, NC. 